\title{
Activity of robusta coffee on the expression of CRP and MMP-9 against hyperlipidemia
}

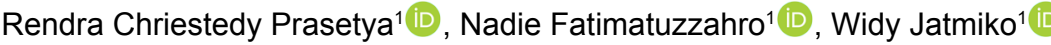

${ }^{1}$ University of Jember, Biomedical Department, Jember, Indonesia

Contact authors: rendra.fkg@unej.ac.id, nadiefatima@gmail.com, widyj@rocketmail.com

Received in March 31, 2020 and approved in May 6, 2020

\begin{abstract}
Hyperlipidemia especially LDL accumulation causing inflammation in blood vessel. CRP and MMP-9 are component that triggering in inflammation process. This study to know activity of robusta coffee against hyperlipidemia on this component. This study using male wistar rats were divided into three groups ; normal, hyperlipidemia and that were given coffee with high fat diet groups. Robusta coffee was given $3.6 \times 10^{-6} \mathrm{~m}^{3}$ by intragastric gavage. Blood collection was carried out using infra-orbital for analysis of LDL levels. Furthermore, the experimental animals were sacrificed and coronary arteries were taken for CRP and MMP-9 immunohistochemical staining. Data were analyzed using ANOVA followed LSD test. Results show The highest expression score for CRP and MMP-9 within the hyperlipidemia group was $188.27 \pm 1.8$ and $277.56 \pm 2.1$. The decrease in the expression score of CRP and MMP-9 happened within the ones that were given coffee with $59.33 \pm 1.5$ and $116.7 \pm 0.2$ each. Results showed that were differences in the expression of CRP and MMP-9 in all groups $(\mathrm{p}<0.05)$. In conclusion, activity robusta coffee can decreases the expression of CRP and MMP-9 against hyperlipidemia.
\end{abstract}

Key words: Coronary disease; hyperlipidemia; robusta coffee.

\section{INTRODUCTION}

Hyperlipidemia is a condition where the High Density Lipoprotein (HDL) decreases and cholesterol levels, triglycerides and Low Density Lipoprotein (LDL) increase (Anthony et al., 2012). The phenomena caused LDL accumulation on the blood vessel wall, causing oxidative stress, which would decrease the bio-availability of Nitric Oxide (NO) and increase the Reactive Oxygen Species (ROS).

The increasing level of ROS will cause the oxidation of LDL and turn it into ox-LDL which, then, will be processed as a foreign object that induced the CRP secretion, which is an acute phase within the liver Chung, Makambi and Soldin (2014), Bentzon (2014). CRP functions during the opsonization mechanism of oxLDL, triggering the phagocytosis process and forming foam cells (Calabro; Golia; Yeh, 2009). The accumulation of foam cell will form fibro-fatty lesion which then maturate and form a mature atherosclerotic plaque (fibrous cap). Fibrous cap consists of two main components: the center rich in lipids and the extracellular matrix, that contains collagen and protein (Bentzon, 2014). CRP also induce MMP-9 secretion with the endothelium cell (Fonseca; Lima; Couto, 2014).

The result of the research shows that there is an escalation of matrix metalloproteinase-9 (MMP-9) expression, in addition to the core of fibrous cap (Yabluchanskiy, 2012). MMP-9 has a role in the degradation of collagen and elastin, immune response stimulation during the early stage of pathogenesis and disease progression, sitokin and kemokin activity. The higher MMP-9, the thinner the matrix extracellular component (collagen) in the fibrous cap which will cause the fibrous cap to become unstable and rupture (Newby, 2015). The phenomena can cause various complications such as coronary disease, when the coronary artery ruptures until antioxidant substance that can be found in coffee is needed.

Coffee contains phytopharmaceutical substances that may potentially act as antioxidants. There are various types of coffee that contain phytopharmaceutical substances, one of them is Robusta, that which has more fitofarmaka more phytopharmaceutical substances than others (Farah, 2012). Robusta coffee contains several alkaloids and polifenol substances such as caffeine, chlorogenic acid (CGAs), ferulic acid (FA), and Dihydrocaffeic acid (DHCA) (Farah, 2012). Caffeine has the effect to enhance the cell migration of the endothelium and re-endotheliumination, CGAs acts as an antitumor and MMP-9 inhibitor, FA acts as a potent antioxidant; DHCA acts as an MMP-2 inhibitor and MMP-9 for the cerebral ischemic rats model (Lee; Lee; Bu, 2015; Silva; Batista, 2017; Fang et al., 2012). Based on the explanation, the writers aim to find out the effect of Robusta coffee on CRP and MMP-9 expression against hyperlipidemia.

\section{MATERIAL AND METHODS}

This research has the ethical clearance from the ethical committee of the Faculty of Dentistry of University of Jember No. 256/UN25.8/KEPK/DL/2019. The material of this research were follows : fifteen of 2-3 month male wistar rats (LPPT UGM, Yogyakarta) were randomly divided into three groups. One, control group was fed with normal food (Feedmill-Malindo, Gresik), second is hyperlipidemia group was fed with high fat diet food. High fat diet food making is 
done by mixing $0,003 \mathrm{~kg}$ of pig fat and $0,002 \mathrm{~kg}$ of duck egg yolk (Harsa, 2014), and the third group is coffee group was fed with high fat diet food and coffee solution $3.6 \times 10^{-6} \mathrm{~m}^{3}$. Coffee powder (PTPN XII, Jember) solution making by conversion coffee dose in humans . After the conversion is done, the rats are given $18 \mathrm{~kg} \cdot \mathrm{m}^{-3}$ ground coffee were diluted into boiling water $\left(100{ }^{\circ} \mathrm{C}\right)$. Experimental animals were grouped into three groups: control group, hyperlipidemia and coffee group . Both groups with hyperlipidemia and those given coffee were treated with a high-fat diet, with $5 \times 10^{-6} \mathrm{~m}^{3}$ every morning using intragastric gavage. Subsequently, the ones given coffee with $3.6 \times 10^{-6} \mathrm{~m}^{3}$ by intragastric gavage too. After 4 weeks, the experimental animals were anesthetized using Ketamine $\mathrm{HCl}$ (Phzer Co). Then, euthanasia was then carried out and the coronary artery was taken by the cardiac surgery. The process of coronary artery extraction was done carried out by taking a longitudinal cut below $3 \mathrm{~mm}$ from the atrial and ventricular border (Eckman et al., 2013). The heart organ was fixed into PBS (Phosphate Bufer Saline/Sigma) solution for $24 \mathrm{~h}$. The next step was the histochemical process, before cutting the liquid paraffin. Immunolocalization of CRP and MMP-9 expression using CRP kit antibody (1:200 dilution, Santa $\left.\mathrm{Cruz}^{\circledR}\right)$ and MMP-9 kit antibody (1:400 dilution, Santa Cruz $\left.{ }^{\circledR}\right)$, DAB (Diamonobenzinidine/Daco), HRP (horseradish peroxidase) and was left for one night at $4{ }^{\circ} \mathrm{C}$. After this, the object was then observed under a microscope with 400x magnification. Expressions of CRP and MMP-9 were calculated using histo score (h-score) (Indriani; Saputra; Maker, 2017).

\subsection{Statistical Analysis}

Result are reported as mean \pm standart deviation. Differences between groups were compared using ANOVA test. $P<0.05$ was followed LSD test.

\section{RESULTS}

\subsection{CRP and MMP-9 Expression}

CRP and MMP-9 expression scores were measured using the $\mathrm{H}$-score showing on average, the highest CRP and MMP-9 expression was found in the group with hyperlipidemia with $188.27 \pm 1.88$ and $277.56 \pm 0.48$ each. For the groups to which coffee was given, a decline towards the number of $59.33 \pm 1.50$ and $116.07 \pm 1.02$ was observed to the average CRP and MMP-9 expression of the control group (Figure 1).

The highest expression of CRP and MMP-9 was found in the hyperlipidemia group which was characterized by a deeper brown color intensity than the control group and the coffee treatment group. The lightest brown color occurred within the control group, while in the coffee treatment group there is was a touch of brown with moderate intensity (Figure 2).

One Way Anova test result had a significant value ( $p$ $<0.05$ ), which shows a significant difference in the CRP and MMP-9 expression scores in all groups (Table 1). To determine the difference in CRP and MMP-9 expression scores between treatment groups, a post hoc LSD test was performed. The LSD test showed a significant difference between all treatment groups $(\mathrm{p}<0.05)$.

\section{DISCUSSION}

The result of this study shows that there is an increase in LDL levels in the hyperlipidemia group compared to the coffee treatment group and the control group. This condition occurs due to the deposit of lipids in hepatocytes are metabolized into triglycerides and cholesterol esters. Cholesterol esters in LDL will be carried to the liver and steroidogenic tissues such as the

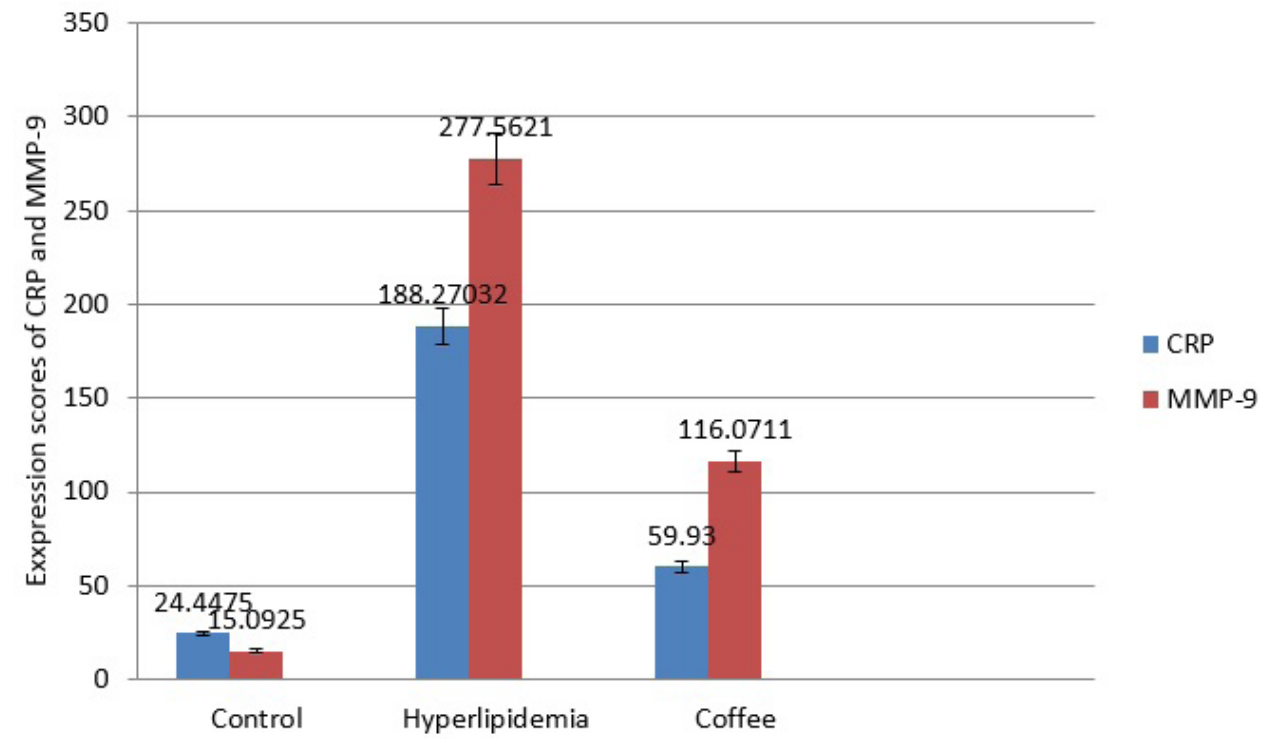

Figure 1: CRP and MMP-9 expression scores using $\mathrm{H}$-Score. 
adrenal glands, testicles, and ovaries that have LDL cholesterol receptors. Some LDL cholesterol will experience oxidation which will trigger an inflammatory response (Sudoyo et al., 2010).
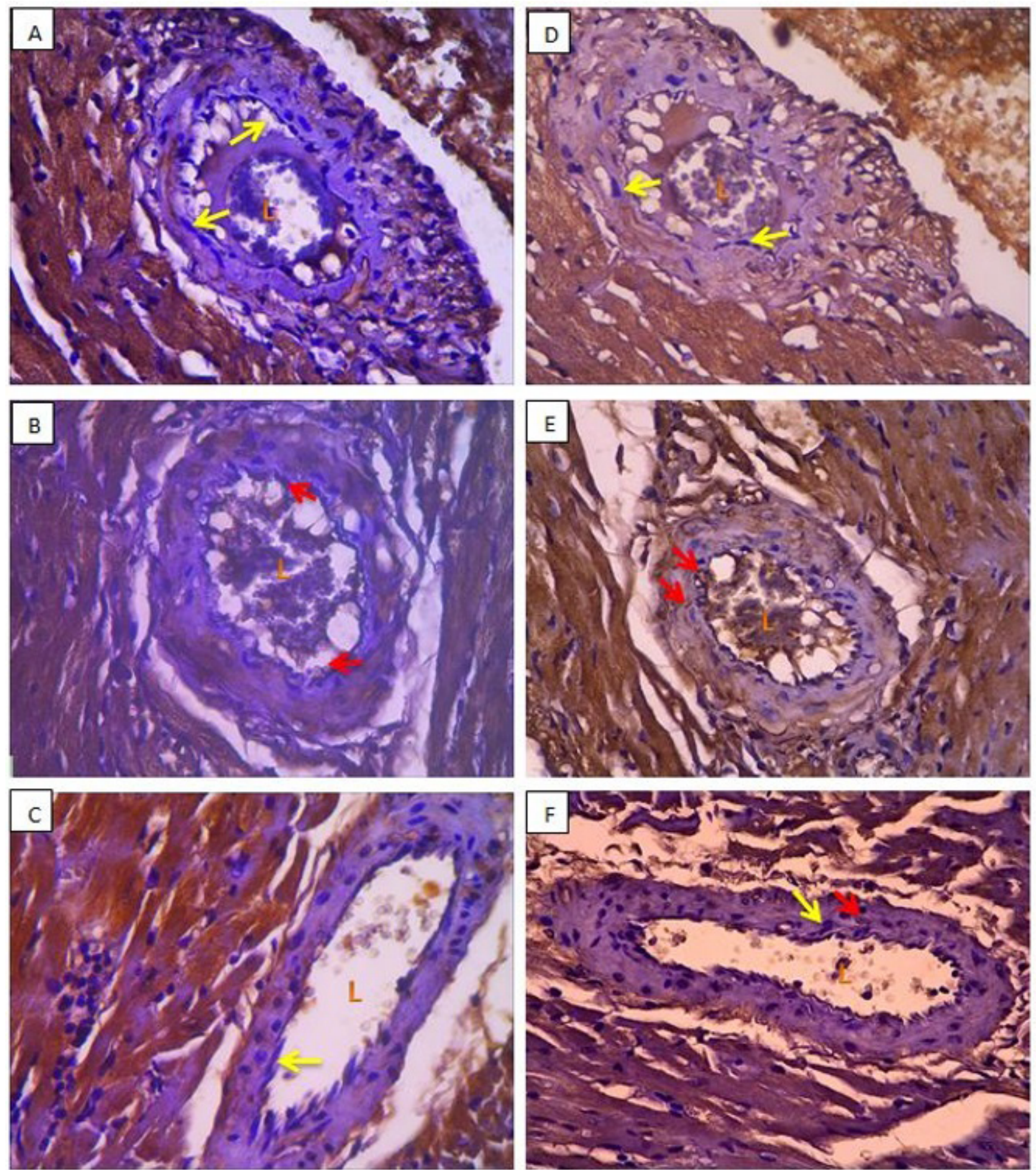

Figure 2: An immunohistochemical description of coronary artery preparations with an-adjustment of $400 \mathrm{x}$. CRP expression is shown in figures (A), (B), and (C). MMP-9 expression is shown in figures (D), $(E)$, and (F). Control group (A) and (D), hyperlipidemia group $(B)$ and $(E)$, and treatment groups of coffee $(C)$ and $(F)$. The yellow arrow shows endothelium cells that do not express $C R P$ and MMP-9, while the red arrow shows endothelium cells that express CRP and MMP-9. Description: $L$ (lumen). 
Table 1: Summary ANOVA test result CRP and MMP-9 expression score.

\begin{tabular}{cccccc}
\hline & Sum of Squares & df & Mean Square & F & Sig. \\
\hline CRP & Between groups & 75393.140 & 2 & 37696.570 & 4.08453 \\
\hline Within Groups & 83.080 & 9 & & & \\
\hline Total & 75476.220 & 11 & & 3.67554 \\
\hline MMP 9 9 & Between groups & 140122.562 & 2 & 70061.281 & .000 \\
\hline Within Groups & 17.158 & 9 & 1.906 & \\
\hline Total & 140139.720 & 11 & & \\
\hline
\end{tabular}

Based on the result of this study, it seems that the CRP and MMP-9 expression are the most intense in the endothelium cells when the artery group with hyperlipidemia is given a high-fat diet. Increased expression of CRP and MMP-9 occurs as a result of continuous inflammation by oxLDL. The inflammatory process that occurs begins with an increase in Reactive Oxygen Species (ROS) and a decrease in the bioavailability of Nitric Oxide (NO) so that endothelium cells experience dysfunction and increased permeability. This causes LDL to oxidize to form oxLDL (Wu et al., 2017). The process, will trigger CRP secretion by hepatocyte cells (Chung; Makambi; Soldin, 2014).

CRP plays an active role in endothelium dysfunction and the formation and development of atherosclerotic plaques, where it has been found in atherosclerotic plaques. CRP performs down-regulated transcription of endothelial nitric oxide (NO) synthase (eNOS) in endothelium cells, resulting in a decrease in the amount of released NO. This inhibition of NO production facilitates apoptotic endothelium cells. CRP also regulates intercellular adhesionmolecular 1 (ICAM-1), VCAM-1, and E-selectin adhesion molecules. Besides, CRP stimulates the migration and proliferation of vascular smooth muscle cells, neointimal formation, and ROS production. Another mechanism by which CRP actively participates in atheroma formation is facilitating through the opsonization of LDL by macrophages which then becomes foam cells and develops into atheroma plaques (Montero et al., 2006; Cardoso; Paulos, 2017). CRP can induce MMP-9 secretion by smooth muscle cells that cause instability in atheroma plaques (Fonseca; Lima; Couto, 2014).

Decreased expression of CRP and MMP-9 occurrs in the coffee treatment group compared to the hyperlipidemia group. Decreased expression of CRP and MMP-9 in the coffee treatment group is suspected due to the content of phytopharmaceutical compounds found in coffee. Chlorogenic acid (CGAs) has an anti-inflammatory effect by inhibiting the secretion of pro-inflammatory cytokines in PBMC (Peripheral Blood Mononuclear Cells) (Krakauer, 2002). Chlorogenic acid (CGAs) plays an important role as an anti-tumor agent through inhibition of MMP-9 and it has been proven to inhibit MMP-9 (Marco; Fischer; Henle, 2011; Jin et al., 2005). Based on the results of existing studies, it is proven that CGAs and caffeine are effective in inhibiting the signals of PKD, IKK, NF-kB and IL-8 which are inflammatory pathways through the binding of intracellular ROS. In addition, the mechanism of CGAs and kefins in inhibiting MMP-9 expression is related to other transduction signals such as antioxidant and redox signaling pathways, which can increase HO-1 (Heme Oxygenase-1) and NQO-1 regulation (NAD (P) H dihydrogenase), which are antioxidant enzymes and have been known to act as a protector of endothelium cells against oxidative stress. The regulatory mechanisms of HO-1 and NQO-1 occur through activation of Nrf-2 (Nuclear factor erythroid 2-related factor 2) and Akt phosphorylation which is also known as kenase-B proteins (Shin et al., 2017).

Another coffee component, ferulic acid, inhibits the expression of CRP and MMP-9 through 5 main pathways by direct binding to ROS, stabilizing unstable molecules by donating one electron, inhibiting oxidative enzymes, such as xanthine oxidase, protein kinase $\mathrm{C}$, and others resulting in a reduction in ROS production, binding of transition metals such as $\mathrm{Fe}^{2+}$ and $\mathrm{Cu}^{2+}$ involved in the conversion of $\mathrm{O}_{2-}$ and $\mathrm{H} 2 \mathrm{O}$ into free radicals, and repairing damage that occurs in cells such as damage to membrane lipids, proteins, and deoxyribonuceat acid (DNA) cells (Silva; Batista, 2017). The mechanism of inhibition of free radicals by ferulic acid causes inhibition of the pro-inflammatory secretion of cytokines so that it can reduce the expression of CRP and MMP-9 in endothelium cells in the intima of the rats' coronary artery (Fang et al., 2012; Lampiasi; Montana, 2016). Another coffee substance that has positive effects is dihydrocaffeic acid (DHCA). Based on existing in vitro studies showing that DHCA at a concentration of $100 \mu \mathrm{g} \cdot \mathrm{mL}^{-1}$ can inhibit MMP-9 and MMP-2 in the mouse model of cerebral ischemia (Lee; Lee; $\mathrm{Bu}, 2015$ ).

MMP-9 expression in the control group is lower than that in the hyperlipidemia group and coffee treatment group. This happens since the control group is the only one that is 
given a standard diet so that LDL does not occur in the intima tunica. In general, under normal conditions MMP-9 is also secreted to normal limit but if there is inflammation there will be an increase in MMP-9 (Wulandari et al., 2016).

The LSD test result shows a significant difference between groups. A significant difference between the coffee treatment group and the hyperlipidemia group shows that coffee intake can reduce MMP-9 expression. Decreasing MMP-9 expression occurs due to the coffee content which has anti-inflammatory and anti-oxidant effects.

\section{CONCLUSION}

Robusta coffee can reduce the expression of CRP and MMP-9 in coronary artery endothelium cells that are induced by hyperlipidemia.

\section{REFERENCES}

ANTHONY, S. F. et al. Harrison's Principles of Internal Medicine Volume II. 18th Ed. United States of America: McGraw-Hill. 2012. 134p.

BENTZON, J. F. et al. Mechanisms of plaque formation and rupture. Circulation Research, 114(12):1852-1866, 2014.

CALABRO, P.; GOLIA, E.; YEH, E. T. CRP and the risk of atherosclerotic events. Seminars in Immunopathology, 31:79-94, 2009.

CARDOSO, I. L.; PAULOS, A. N. C Reactive Protein (CRP) and cardiovascular disease. International Archives of Cardiovascular Disease, 1(1):1-11, 2017.

CHUNG, S. H.; MAKAMBI, K. H.; SOLDIN O. P. Tobacco smoke exposure, C-reactive protein and steroid hormones measured by Tandem Mass Spectrometry in healthy women. Journal of Steroids and Hormonal Science, 5(4):1-6, 2014.

ECKMAN, D. M. et al. Weekly doxorubicin increases coronary arteriolar walland adventitial thickness. Plos One, 8(2):1-6, 2013.

FANG, Y. C. et al. Bioactivities of crude caffeine: Antioxidant activity, cyclooxygenase- 2 inhibition, and enhanced glucose uptake. Food Chemistry, 131(2):564$568,2012$.

FARAH, A. Coffee: Emerging Health Effects and Disease Prevention. Oxford: Wiley- Blackwell, 2012.45p

FONSECA, A. L.; LIMA, F.; COUTO, R. D. The action of metaloproteinase in atherosclerosis diseases. ABCS Health Science, 39(3):186-193, 2014.
HARSA, I. M. S. Efek Pemberian Diet Tinggi Lemak terhadap Profil Lemak Darah Tikus Putih (Rattus Norvegicus). Jurnal Ilmiah Kedokteran, 3(1):21-28, 2014.

INDRIANI, V.; SAPUTRA, H.; MAKER, I. I. P. L. Poly (ADP Ribose) polymerase-1 Overexpression as A Predictive Factor for Poor Chemotheraphy Outcome in Triple Negative Breast Cancer. International Journal of Science and Research, 6(11):1881-1885, 2017.

JIN, U. H. et al. A phenolic compound, 5- caffeoylquinic acid (chlorogenic acid), is a new type and strong matrix metalloproteinase-9 inhibitor: Isolation and identification from methanol extract of Euonymus alatus. Life Sciences, 77(9):60-67, 2005.

KRAKAUER, T. The polyphenol chlorogenic acid inhibits staphylococcal exotoxin-induced inflammatory cytokines and chemokines. Immunopharmacol Immunotoxicol, 24(9):113-120, 2002.

LAMPIASI, N.; MONTANA, G. The molecular events behind ferulic acid mediated modulation of IL- 6 expression in LPS-activated Raw 264.7 cells. Immunobiology, 221(4):86-93, 2016.

LEE, K.; LEE, B. J.; BU, Y. Protective effect of dihydrocaffeic acid, a coffee component metabolite, on a focal cerebral ischemia rat model. Molecules, 119(20):30-40, 2015.

MARCO, L. M.; FISCHER, S.; HENLE, T. High molecular weight coffee melanoidins are inhibitors for matrix metalloproteases. Journal of Agricultural and Food Chemistry, 12(59):417-423. 2011.

MONTERO, I. et al. C-reactive protein induces matrix metalloproteinase- 1 and -10 in human endothelial cells: Implications for clinical and subclinical atherosclerosis. Journal of the American College of Cardiology, 47(7):1369-1378, 2006.

NEWBY, A. C. Role of metalloproteinase in plaque rupture. International Journal of Gerontology, 1(3):103-111, 2015.

SHIN, H. S. et al. Catechol Groups Enable Reactive Oxygen Species Scavenging-Mediated Suppression of PKDNFkappaB-IL-8 Signaling Pathway by Chlorogenic and Caffeic Acids in Human Intestinal Cells. Journal of Nutrient, 9(2):66-72, 2017.

SILVA, E. O.; BATISTA, R. Ferulic acid and naturally occurring compounds bearing a feruloyl moiety: A review on their structures, occurrence, and potential health benefits. Comprehensive Reviews in Food Science and Food Safety, 16(2):580-616, 2017.

SUDOYO, A. W. et al. Buku Ajar Ilmu Penyakit Dalam. Jakarta: Interna Publishing. 2010. p.1984-1992. 
WU, M. Y. et al. New insight into the role of inflammation in the pathogenesis of atherosclerosis. International Journal of Molecular Science, 18:1-18, 2017.

WULANDARI, L. R. et al. Efek pemberian matrix metalloproteinase-9 (MMP-9) RNA interference terhadap ekspresi MMP-9 pada kultur sel endotel vaskular. Jurnal Kedokteran Brawijaya, 22(6):50-57, 2016.

YABLUCHANSKIY, A. et al. Matrix metalloproteinase-9: Many shades of function in cardiovascular disease.

Physiology, 28(5):391-403, 2012. 